\title{
Male with Deletion 9p Terminal Syndrome with Sexual Development Disorder
}

DOI: $10.46932 / \mathrm{sfjdv} 3 \mathrm{n} 1-075$

Received in: Jan 30st, 2021

Accepted in: Feb 1th, 2022

Isabel Alicia Loya Aguilar

Third year Resident Doctor in Medical Genetics

Genetics Service, Centro Médico Nacional 20 de Noviembre ISSSTE.

San Lorenzo 502, building E, $1^{\text {st }}$ floor, Col. Del Valle México City. Zip Code 03100.

E-mail: isaloya.md@gmail.com

M.D. María del Carmen Chima-Galán

Responsible of Medical Genetic Service

Centro Médico Nacional 20 de Noviembre ISSSTE.

San Lorenzo 502, building E, $1^{\text {st }}$ floor, Col. Del Valle México City. Zip Code 03100.

E-mail: carmenchimag@yahoo.com.mx

\section{Liliana García-Ortiz}

Medical Genetics, Medicine Genomics Division and Clinical Genetics

Centro Médico Nacional 20 de Noviembre ISSSTE.

San Lorenzo 502, building D, 2nd floor, Col. Del Valle México City. Zip Code 03100.

E-mail: garortiz@yahoo.com

\section{Yuritzi Santillán Hernández}

Medical Genetics, Medical Genetics Service.

Centro Médico Nacional 20 de Noviembre ISSSTE.

San Lorenzo 502, building E, $1^{\text {st }}$ floor, Col. Del Valle México City. Zip Code 03100.

E-mail: yuritzisantillan@yahoo.com

\begin{abstract}
Introduction: The 9p deletion syndrome is a genomic disorder characterized by trigonocephaly, facial dysmorphism, genital anomalies and developmental delay. The size of the deletion in $9 \mathrm{p}$ is variable and there has been several attempts to propose a critical region, although there is no region yet recognized for this syndrome. The phenotype-genotype correlation could be associated to the break-points of the deletion, as well as the size and genes involved in the deleted region of $9 \mathrm{p}$; since there are several genes involved in brain, embryologic, sexual development, cranial morphogenesis, transcription factors and others in the short arm of chromosome 9. This article presents a case of $9 p$ terminal deletion with different clinical features to the consensus phenotype of $9 \mathrm{p}$ deletion syndrome, whose first approach was through the disorder of sexual development (DSD). Case report: Infant of 23 months referred to Genetics for clitoromegaly, without any familiar history, product of the second gestation of a normal pregnancy, without any perinatal complications and female sex assigned at birth. In the physical exam: normocephalic, facial dysmorphisms, and genital anomalies. We begin protocol for DSD finding karyotype formula of 46,XY,del(9)(p22). Discussion: It has been postulated that haploinsufficiency of the genes involved in $9 p$ deletion combined with genomic variants are responsible for the phenotype variability, this maybe the reason why our patient does not present the classical phenotype. It is important to have a multidisciplinary team for management and follow-up with these patients for an adequate male
\end{abstract}


sex assignment and treatment for any complications associated to the syndrome, if possible, in order to have a better quality of life.

Keywords: de19p(22), neurodevelopmental disorders and sexual differentiation.

\section{INTRODUCTION}

The 9p deletion syndrome (OMIM: 158170) is a genomic disorder with an incidence in less than 1:1,000,000. The first report case was in 1972 by Alfi et al., since then over 700 cases have been reported worldwide. (Alfi et al., 1973).

It is characterized by a variable phenotype that includes developmental delay, facial dysmorphisms (trigonocephaly or brachycephaly, blepharophimosis, hypertelorism, long philtrum, micrognathia, lowset posterior hair-line) digital anomalies (long medium phalanges with short distal phalanges), in males genitourinary anomalies (cryptorchidism, hypospadias, ambiguous genitalia, testicular dysgenesis and higher risk for gonadoblastoma), other anomalies that have been reported are congenital hypothyroidism and cardiac defects. (Hou et al., 2016; Huret et al., 1988)

Around two thirds of $9 \mathrm{p}$ deletion cases are de novo or sporadic, due to a deficient paternal or maternal meiosis and the remaining third is the result of unbalanced rearrangements inherited by either parent carrying a balanced translocation. (Van Ravenswaaij et al., 2005)

In the literature there are studies in which the size of deletion is variable and even with several attempts to reach a critical region between 4-6 Mb (Kawara et al., 2006; Sams et al., 2022), there is no region yet recognized for this syndrome. Most of the patients have either a pure terminal deletion that involves the short arm of chromosome 9 or big unbalanced chromosomic rearrangements up to $18.9 \mathrm{Mb}$ (Ng et al., 2020).

Therefore, the genotype-phenotype correlation could be associated to the break-point position of the deletion $9 \mathrm{p}$ region, which could be proximal, interstitial, distal or pericentric, since chromosome 9 involves several genes associated with cerebral, embryologic and sexual development as well as for cranial morphology, signaling networks associated to the bone morphogenic protein (BMP), transcription factors, initiation of transcription, etc. (Sams et al., 2022) (Figure 1).

This article presents a case of $9 p$ terminal deletion with different clinical features to the consensus phenotype of 9p deletion syndrome, whose first approach was through the disorder of sexual development (DSD). 


\section{CASE REPORT}

Patient with clitoromegaly referred to the Genetics service for diagnosis approach, no family history is denoted. Product of the second gestation of non-consanguineous parents, mother of 38 years and father of 32 years at moment of birth. Pregnancy was normal, obstetric ultrasound without any anomalies. He was born at 38 weeks of gestation by $\mathrm{C}$-section due to acute fetal suffering and without any perinatal complications, weight $(3500 \mathrm{~g})$ and length $(50 \mathrm{~cm})$ were normal and female sex was assigned.

At moment of Genetic assessment, we found an infant of 1 year and 11 months with development milestones delay, weight $5,900 \mathrm{~g}\left(50^{\text {th }}\right.$ percentile), length $62 \mathrm{~cm}\left(90^{\text {th }}\right.$ percentile $)$ and $\mathrm{CP} 41 \mathrm{~cm}\left(75^{\text {th }}\right.$ percentile). Normocephalic, low-set ears, prominent forehead, arched eyebrows, hypertelorism, wide and depressed nasal bridge, short columella, flattened nasal tip, down-slated lip corners, thin upper lip and micrognathia (Figure 2). Genitals with micro-penis, proximal interscrotal hypospadias, scrotalized labia majora, bilateral cryptorchidism, presence of gonads in inguinal canal. Prader stage IV virilization. (Figure $3)$.

Renal ultrasound reports right kidney $5.3 \times 2.3 \times 2.8 \mathrm{~cm}$ and volume $17.8 \mathrm{cc}$, left kidney $5.2 \times 2 \times 2.1 \mathrm{~cm}$ and volume $15.8 \mathrm{cc}$, pyelocaliceal system without dilations. Pelvic ultrasound without uterus or any other female structure. Inguinal ultrasound with suggested data for presence of testicles in suprainguinal region. Echocardiography without any structural anomalies.

Additionally, a hormonal test curve (2500 IU of HCG) demonstrates an elevated testosterone of more than 50\%. (Table 1).

Karyotype with GTG banding technique demonstrated a terminal deletion of short arm of chromosome 9. 46,XY,del(9)(p22) (Figure 4). The parent's karyotypes are reported normal.

\section{DISCUSSION}

There are around 700 cases of $9 p$ deletion syndrome, where the phenotype-genotype variability depends on the size of the deletion and the genes involved. It has been postulated that haploinsufficiency of the genes involved in $9 \mathrm{p}$ deletion combined with genomic variants are responsible for the phenotype variability ( $\mathrm{Ng}$ et al., 2020); this is possibly the reason why our patient does not present trigonocephaly.

The neurodevelopment anomalies are the main manifestations of $9 \mathrm{p}$ deletion syndrome, which is present in $100 \%$ of the patients, like this patient who is a year and 11 months and has able to seat or pronounce monosyllables, which represents a developmental milestones delay. (Van Ravenswaaij et al., 2005). 
There are reports that nearly the $30 \%$ of patients with 9p deletion have congenital heart anomalies like PCA, IAC, IVC, tricuspid insufficiency and aortic coarction; our patient does not have any of these anomalies due to the low percentage of presentation (Swinkels et al., 2008).

Ultimately, DSD is present in more than $50 \%$ of the male patients with this syndrome presenting with micro-penis and hypospadias, like this case report; where the DMRT1 and DMRT2 genes, evolutionary conserved have been associated with sex determination in males. (Swinkels et al., 2008).

We consider necessary to amplify the genetic analysis with molecular tests of high resolution to delineate de break-points and the group of genes that are participating in the $9 p$ deleted region in our patient.

After de genetic diagnosis, it is fundamental a multidisciplinary follow-up focused in the most frequent complications of the 9p deletion syndrome to avoid any complications in misassignment of sex in male patients, neurologic and behavioral disorders, as well as to carefully strategy the management of neurological or cardiological sequels.

\section{CONCLUSION}

Patients with 9p deletion syndrome have a phenotypic variability, depending in the size of the region and the genes involved. Our patient is part of these cases where the clinical characteristics differ from the consensus characteristics. We consider necessary the amplification of the genetic analysis of the deleted region of $9 p$ to delineate the genes that are participating in the etiology to allow us the explanation of the phenotypic variability with the purpose to bring a specialized medical attention and follow-up for the anticipation of possible complications.

In our patient for the quantity of genes deleted we suspect a strong intellectual deficit is present and disorders of speech and language will develop this is why a psychometric evaluation should be performed when the right age is reached as well as language therapy specially with a model like the proposed by Vivero Riquelme in her work ". Proposal for individual intervention for language development in early childhood education“ (Riquelme, 2022) since this model has a personal approach depending in the child's need. 


\section{REFERENCES}

Alfi, O., Donnell, G. N., Crandall, B. F., Derencsenyi, A., \& Menon, R. (1973). Deletion of the short arm of chromosome no.9 (46,9p-): A new deletion syndrome. Annales De Genetique, 16(1), 17-22.

Hou, Q.-F., Wu, D., Chu, Y., \& Liao, S.-X. (2016). Clinical findings and molecular cytogenetic study of de novo pure chromosome 9p deletion: Pre- and postnatal diagnosis. Taiwanese Journal of Obstetrics \& Gynecology, 55(6), 867-870. https://doi.org/10.1016/j.tjog.2016.11.001

Huret, J. L., Leonard, C., Forestier, B., Rethore, M. O., \& Lejeune, J. (1988). Eleven new cases of del(9p) and features from 80 cases. Journal of Medical Genetics, 25(11), 741-749. https://doi.org/10.1136/jmg.25.11.741

Kawara, H., Yamamoto, T., Harada, N., Yoshiura, K., Niikawa, N., Nishimura, A., Mizuguchi, T., \& Matsumoto, N. (2006). Narrowing candidate region for monosomy 9p syndrome to a 4.7-Mb segment at 9p22.2-p23. American Journal of Medical Genetics. Part A, 140(4), 373-377. https://doi.org/10.1002/ajmg.a.31094

Ng, J., Sams, E., Baldridge, D., Kremitzki, M., Wegner, D. J., Lindsay, T., Fulton, R., Cole, F. S., \& Turner, T. N. (2020). Precise breakpoint detection in a patient with 9p- syndrome. Cold Spring Harbor Molecular Case Studies, 6(3), a005348. https://doi.org/10.1101/mcs.a005348

Riquelme, M. D. C. V. (2022). Propuesta de intervención individual para el desarrollo del lenguaje en educación infantil: Proposal for individual intervention for language development in early childhood education. South Florida Journal of Development, 3(1), 124-136. https://doi.org/10.46932/sfjdv3n1-009

Sams, E. I., Ng, J. K., Tate, V., Claire Hou, Y.-C., Cao, Y., Antonacci-Fulton, L., Belhassan, K., Neidich, J., Mitra, R. D., Cole, F. S., Dickson, P., Milbrandt, J., \& Turner, T. N. (2022). From karyotypes to precision genomics in 9p deletion and duplication syndromes. Human Genetics and Genomics Advances, 3(1), 100081. https://doi.org/10.1016/j.xhgg.2021.100081

Swinkels, M. E. M., Simons, A., Smeets, D. F., Vissers, L. E., Veltman, J. A., Pfundt, R., de Vries, B. B. A., Faas, B. H. W., Schrander-Stumpel, C. T. R. M., McCann, E., Sweeney, E., May, P., Draaisma, J. M., Knoers, N. V., van Kessel, A. G., \& van Ravenswaaij-Arts, C. M. A. (2008). Clinical and cytogenetic characterization of 13 Dutch patients with deletion 9p syndrome: Delineation of the critical region for a consensus phenotype. American Journal of Medical Genetics Part A, 146A(11), 1430-1438. https://doi.org/10.1002/ajmg.a.32310 


\section{ANEXOS}

Figure 1. Genotype-Phenotype correlations in deletion 9p syndrome.

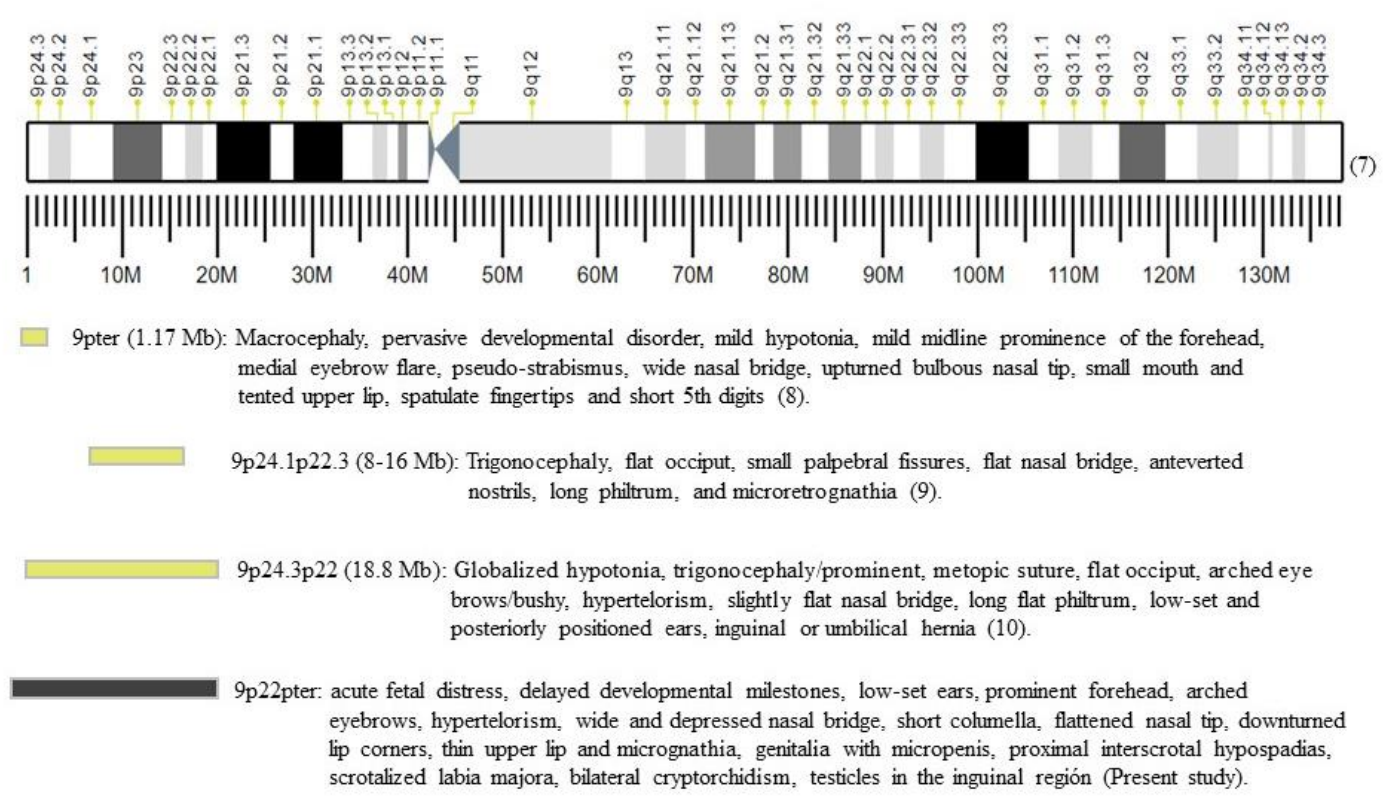

Figure 2. Facial Characteristics: a. Frontal prominence, arched eyebrows. b. broad nasal bridge, short columellae, depressed nasal tip, down-slated lip corners, thin upper lip and micrognathia.
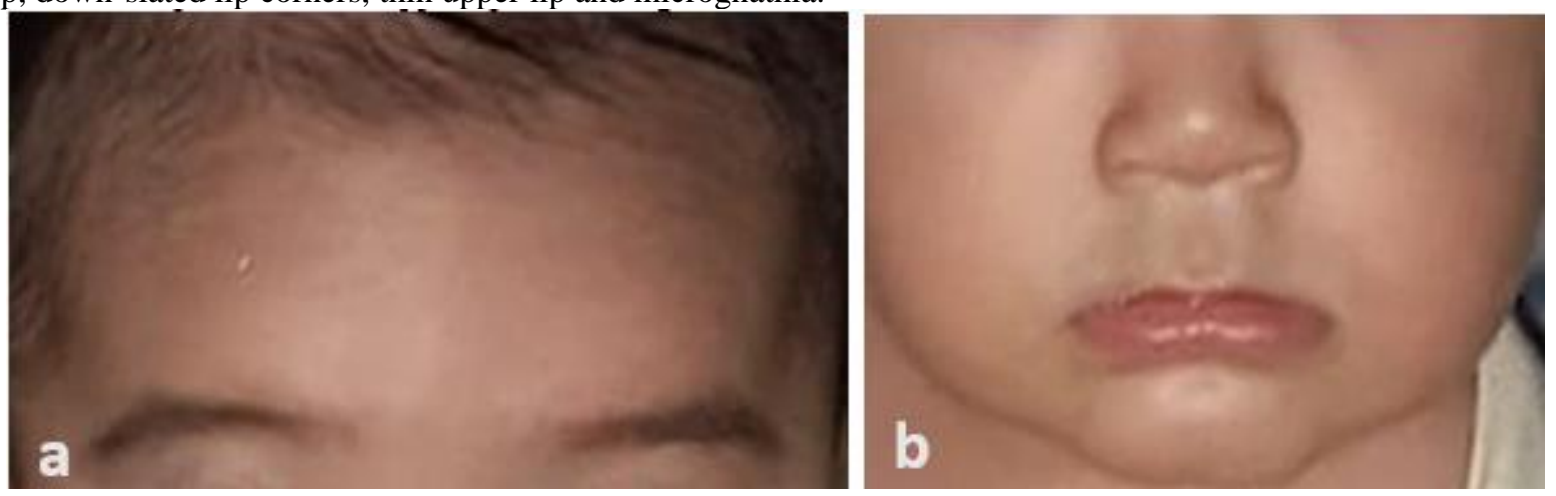

Figure 3. Genital Anomalies: a. Micro-penis and proximal interscrotal hypospadias b. Scrotalized labia majora, bilateral cryptorchidism.
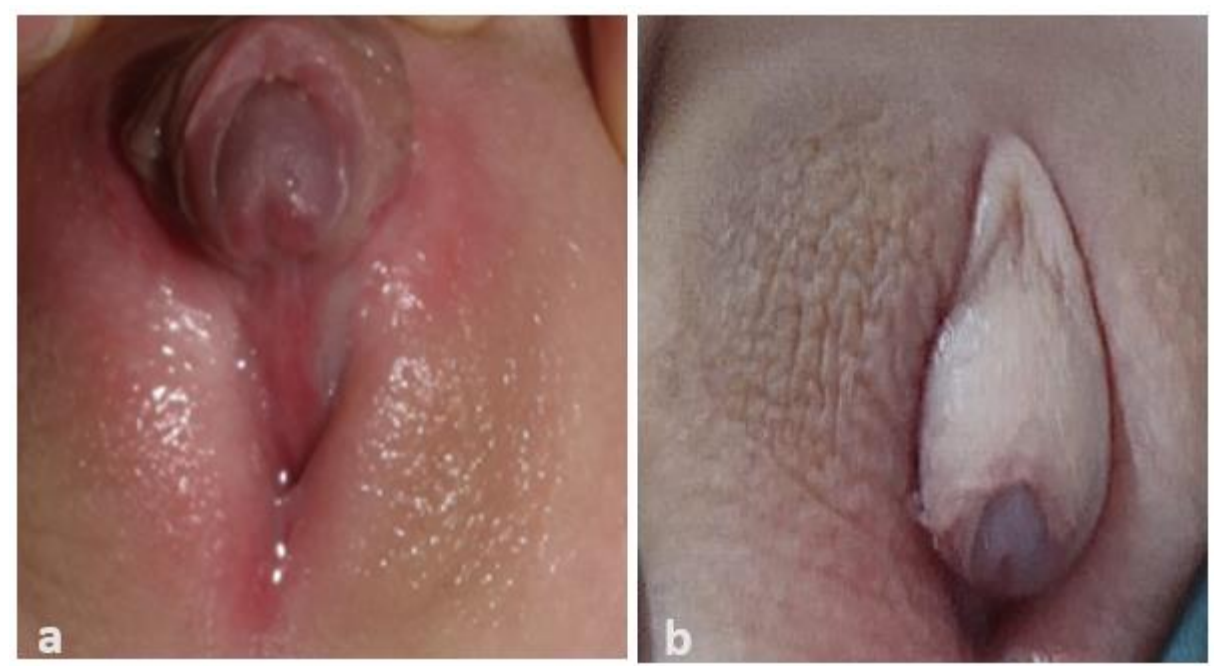
Table 1. HCG stimulation curve.

\begin{tabular}{lcc|} 
Hormonal level & Baseline & $72 \mathrm{hrs}$ \\
FSH $(0.0-2.8 \mathrm{IU} / \mathrm{L})$ & 4.02 & 1.46 \\
\hline LH $(0.0-1.6 \mathrm{IU} / \mathrm{L})$ & 0.792 & 0.405 \\
\hline Estradiol $(30.2-262 \mathrm{pg} / \mathrm{ml})$ & 20.0 & $<20.0$ \\
\hline Testosterone $(0-57.68 \mathrm{ng} / \mathrm{dl})$ & 5.0 & 154 \\
\hline Dehydroepiandrosterone sulfate $(2.3-15 \mathrm{Umol} / \mathrm{L})$ & 0.70 & 0.67 \\
\hline
\end{tabular}

Figure 4. Karyotype 46,XY,del(9)(p22).

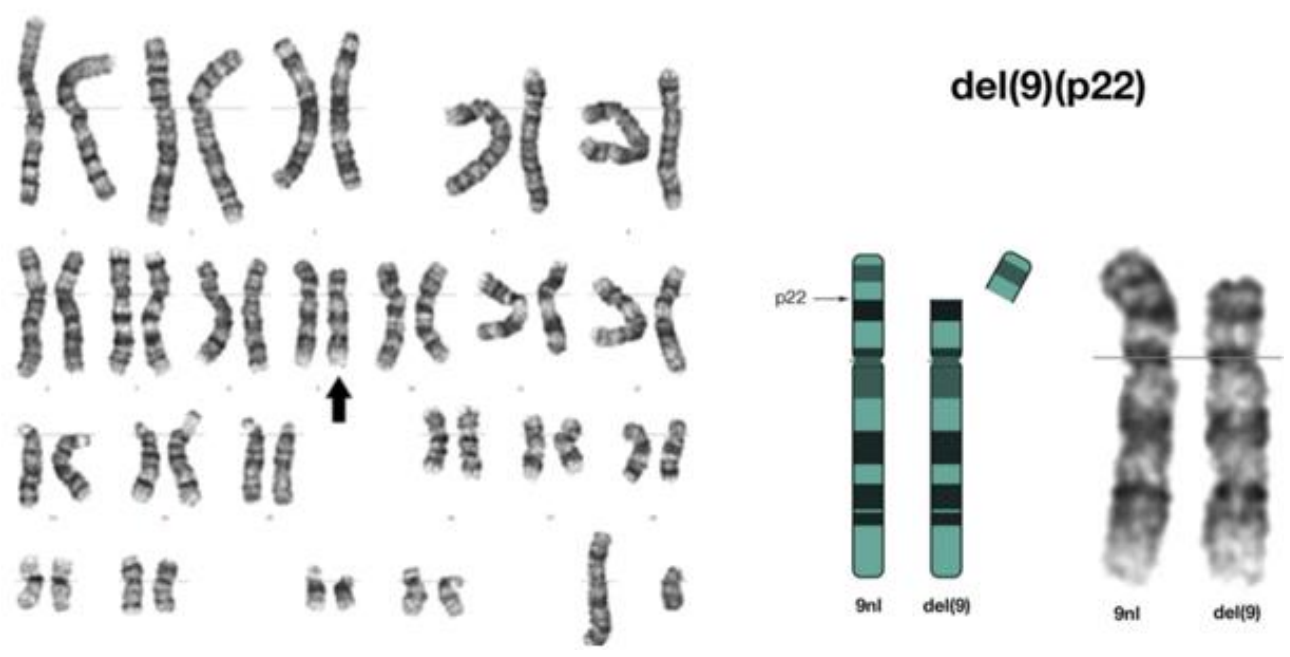

